\title{
Adsorption of Rare Earth Elements from Aqueous Solutions Using Geopolymers ${ }^{\dagger}$
}

\author{
Željka Fiket 1,*, Ana Galović ${ }^{2}$, Gordana Medunić ${ }^{3}$, Martina Furdek Turk ${ }^{1}$, Maja Ivanić ${ }^{1}$, \\ Matej Dolenec ${ }^{4}$, Ivica Biljan ${ }^{2}$, Aleš Šoster ${ }^{4}$ and Goran Kniewald ${ }^{1}$ \\ 1 Division for Marine and Environmental Research, Ruđer Bošković Institute, Bijenička 54, 10000 Zagreb, \\ Croatia; mfurdek@irb.hr (M.F.T.); mivanic@irb.hr (M.I.); kniewald@irb.hr (G.K.) \\ 2 Department of Biology, Faculty of Science, University of Zagreb, Rooseveltov trg 6, 10000 Zagreb, Croatia; \\ anagalovic1303@hotmail.com (A.G.); ibiljan@stud.biol.pmf.hr (I.B.) \\ 3 Department of Geology, Faculty of Science, University of Zagreb, Horvatovac 95, 10000 Zagreb, Croatia; \\ gordana.medunic@gfz.hr \\ 4 Department of Geology, Faculty of Natural Sciences and Engineering, University of Ljubljana, Aškerčeva c. 12, \\ 1000 Ljubljana, Slovenia; matej.dolenec@geo.ntf.uni-lj.si (M.D.); ales.soster@geo.ntf.uni-lj.si (A.Š.) \\ * Correspondence: zeljka.fiket@irb.hr; Tel.: +385-1-456-1036 \\ + Presented at the 1st International Electronic Conference on Geosciences (IECG 2018), 15-30 June 2018; \\ Available online: https://sciforum.net/conference/IECG_2018.
}

Published: 14 June 2018

\begin{abstract}
Rare earth elements, i.e., lanthanides, are important components of many recently developed technology applications. However, their increasing use in the industrial sector, medicine, and agriculture over the last few decades has provided them with the title of "new pollutants". Different methods are now applied for the removal of various pollutants from wastewaters, whereby the emphasis is placed on adsorption due to its simplicity, high efficiency, and low cost. In the present study, geopolymers prepared from coal ash were examined regarding their capacity for the adsorption of lanthanides from model solutions. The obtained results indicate the efficient removal of lanthanides by prepared geopolymers, depicting them as effective adsorbents for this group of elements.
\end{abstract}

Keywords: rare earth elements; geopolymers; adsorption

\section{Introduction}

Rare earth elements (REEs), also known as lanthanides, are important components of many recently developed technology applications and are widely used in the industrial sector, medicine, and agriculture. Although lanthanides are ubiquitous in the environment, their increasing use in the aforementioned sectors over the last few decades has provided them with the title of "new pollutants".

Consequently, an increase in the concentration of lanthanides, especially gadolinium (Gd), in natural water systems was observed over the last two decades [1-4]. The elevated concentrations of gadolinium, up to two orders of magnitude higher than their natural levels, are primarily attributed to the discharge of wastewater, i.e., the application of $\mathrm{Gd}$ in the form of very stable organic complexes for magnetic resonance [2-4].

Nowadays, various processes are used to remove heavy metals from wastewater, e.g., chemical coagulation, ion exchange, extraction, and adsorption. Recently, the emphasis has been placed on adsorption due to the simplicity of the procedure, as well as its high efficiency and low price [5], while zeolites and geopolymers are extensively studied as the most common adsorbents [6-10]. 
Geopolymers can be synthesized from any material with high silicon and aluminum content, regardless of its origin, e.g., natural raw materials such as clay or byproducts of various industrial plants such as ash [6-9]. The activation of fly ash with alkaline solution produces porous alumosilicates, i.e., geopolymers, characterized by an increased specific surface, high pore volume, and the possibility of the adsorption of chemical species that even zeolites cannot remove [6].

The previous studies on the adsorption and stabilization of metals using geopolymers were mainly oriented to heavy metals $(\mathrm{Cd}, \mathrm{Cr}, \mathrm{Cu}, \mathrm{Ni}, \mathrm{Pb}, \mathrm{Zn})[6-9,11,12]$, while the group of lanthanides was not significantly investigated. Sporadic studies mainly dealt with the adsorption of lanthanide on biological materials [13], zeolites [14], and clay [15], but less on geopolymers [16], focusing only on certain lanthanides and rarely on the whole group.

Given the fact that lanthanides are not significantly studied in this regard, our aim was to investigate the ability of geopolymer matrices, prepared from coal ash, to remove lanthanides from model aqueous solutions.

\section{Materials and Methods}

\subsection{Geopolymer Preparation}

The geopolymers were prepared using the Raša coal ash (Istria, Croatia) as the starting material. The characteristics of Raša coal, summarized by Medunić et al. [17], are as follows: total moisture 5.80-19.1 wt\%, ash content 10.3-23.9 $\mathrm{wt} \%$, carbon 58.3-67.5 $\mathrm{wt} \%$, hydrogen $4.10-5.00 \mathrm{wt} \%$, sulfur (organic) $7.90-10.6 \mathrm{wt} \%$, oxygen $5.90-12.9 \mathrm{wt} \%$, nitrogen $1.00-1.80 \mathrm{wt} \%$, and average content of rare earth elements $81.1 \mathrm{mg} \mathrm{kg}^{-1}$ [18].

The Raša coal ash, previously sieved through a 2-mm sieve, was activated with a sodium silicate and $10 \mathrm{M}$ sodium hydroxide solutions to prepare paste specimens (Table 1). A technical-grade sodium silicate solution ( $\mathrm{BDH}$ Prolabo) with $\mathrm{SiO}_{2} / \mathrm{Na}_{2} \mathrm{O}=3.2-3.4\left(\mathrm{Na}_{2} \mathrm{O}=7.5-8.5 \%\right.$, $\mathrm{SiO}_{2}=25.6-27.6 \%$, and $\mathrm{H}_{2} \mathrm{O}=67.75 \%$, with a density of $1.45 \mathrm{~g} \mathrm{~cm}^{-3}$ ) was used as the alkaline activator. Sodium hydroxide solution $(10 \mathrm{M} \mathrm{NaOH})$ was prepared by the dissolution of $\mathrm{NaOH}$ pellets (Fluka, Steinheim, Switzerland) in deionized water. The addition of $10 \mathrm{~mL}$ prepared $\mathrm{NaOH}$ solution modified the molar ratio $\mathrm{SiO}_{2} / \mathrm{Na}_{2} \mathrm{O}$ to $0.7-0.8$ and $1.1-1.3$ in geopolymers $\mathrm{A}$ and $\mathrm{B}$, respectively.

The fresh pastes were exposed to heat curing in a laboratory oven at $75{ }^{\circ} \mathrm{C}$ for $24 \mathrm{~h}$. After two weeks of aging at room temperature, subsamples of prepared geopolymers $\mathrm{A}$ and $\mathrm{B}$ were used for adsorption experiments.

Table 1. Mixture composition for geopolymer preparation.

\begin{tabular}{ccc}
\hline & Geopolymer A & Geopolymer B \\
\hline mash $(\mathrm{g})$ & 50 & 50 \\
$\mathrm{~m}$ Na-silicate $(\mathrm{mL})$ & 7.5 & 15 \\
$\mathrm{SiO}_{2} / \mathrm{Na}_{2} \mathrm{O}$ & $0.7-0.8$ & $1.1-1.3$ \\
\hline
\end{tabular}

\subsection{Adsorption Experiment}

Aqueous solutions containing $1 \mathrm{mg} \mathrm{L}^{-1}$ rare earth elements were prepared from a multi-element reference standard (Analytika, Prague, Czech Republic) containing Ce, La, Nd, and Pm (100 $\pm 0.2 \mathrm{mg}$ $\left.\mathrm{L}^{-1}\right)$ and $\mathrm{Dy}, \mathrm{Er}, \mathrm{Eu}, \mathrm{Gd}, \mathrm{Ho}, \mathrm{Lu}, \mathrm{Sc}, \mathrm{Sm}, \mathrm{Tb}, \mathrm{Tm}, \mathrm{Y}$, and $\mathrm{Yb}\left(20 \pm 0.4 \mathrm{mg} \mathrm{L}^{-1}\right)$. The aliquots $(50 \mathrm{~mL})$ of prepared REEs solution were placed into two plastic bottles (A and B) containing accurately weighed amounts of the sorbents, i.e., geopolymer $\mathrm{A}(\mathrm{m}=0.5003 \mathrm{~g})$ and geopolymer $\mathrm{B}(\mathrm{m}=0.5200 \mathrm{~g})$. The prepared suspensions were shaken using a mechanical shaker at $320 \mathrm{rpm}$. After a certain contact time $(5,15,30,60$, and $120 \mathrm{~min}), 5 \mathrm{~mL}$ of the suspension was taken by a syringe from each bottle and filtered through a $0.45-\mu \mathrm{m}$ filter. Prior to analysis, obtained solutions were diluted 10 times and acidified with $2 \%(v / v) \mathrm{HNO}_{3}$ (65\%, supra pur, Fluka, Steinheim, Switzerland). Lastly, In $\left(1 \mu \mathrm{g} \mathrm{L}^{-1}\right)$ was added as an internal standard. 


\subsection{Rare Earth Elements Analysis}

Multi-elemental analysis of prepared solutions was performed by High Resolution Inductively Coupled Plasma Mass Spectrometry (HR-ICP-MS) using an Element 2 instrument (Thermo, Bremen, Germany). External calibration was used for the quantification. Standards for multi-element analysis were prepared by the appropriate dilution of a multi-element reference standard (Analytika, Prague, Czech Republic) containing Ce, La, Nd, and $\operatorname{Pr}\left(100 \pm 0.2 \mathrm{mg} \mathrm{L}^{-1}\right)$, and Dy, Er, Eu, Gd, Ho, Lu, Sc, Sm, $\mathrm{Tb}, \mathrm{Tm}$, and $\mathrm{Yb}\left(20 \pm 0.4 \mathrm{mg} \mathrm{L}^{-1}\right)$. All samples were analyzed to determine the total concentration of the rare earth elements.

\section{Result and Discussion}

The efficiency of the tested geopolymers as adsorbents for lanthanides was evaluated by determining the concentration of REEs in solution after the specific contact time with a geopolymer $(0,5,15,30,60$ and $120 \mathrm{~min})$. The results presented in Figure 1 demonstrate the decrease of REEs concentration in both solutions (A and $\mathrm{B}$ ). The adsorption onto geopolymers occurred rather fast in the initial phase of the experiment, and already in the first five minutes the REEs concentration decreased to $7-13 \%$ and $23-35 \%$ of the initial concentration in solutions $A$ and B, respectively. Later, the concentrations decreased continuously with time and, at the end of the experiment (120 min), up to $99 \%$ and $96 \%$ of the total REEs were adsorbed onto geopolymers $\mathrm{A}$ and $\mathrm{B}$, respectively. The presented data therefore strongly suggest that both geopolymers are efficient sorbents for REEs and could be efficiently used for their removal from the solution, whereas geopolymer $\mathrm{A}$, which has lower $\mathrm{SiO}_{2} / \mathrm{Na}_{2} \mathrm{O}$ ratios $\left(\mathrm{SiO}_{2} / \mathrm{Na}_{2} \mathrm{O}=0.7-0.8\right)$, has better performance compared to geopolymer $\mathrm{B}$ $\left(\mathrm{SiO}_{2} / \mathrm{Na}_{2} \mathrm{O}=1.1-1.3\right)$. At the end of the experiment, the lowest concentrations in both solutions were measured for $\mathrm{Gd}$, La, and $\mathrm{Tm}(<3 \%$ of the initial concentration), while $\mathrm{Yb}$ and Ho were somewhat less adsorbed compared to the other elements (up to $7 \%$ of the initial concentration remained in the solution).

(a)

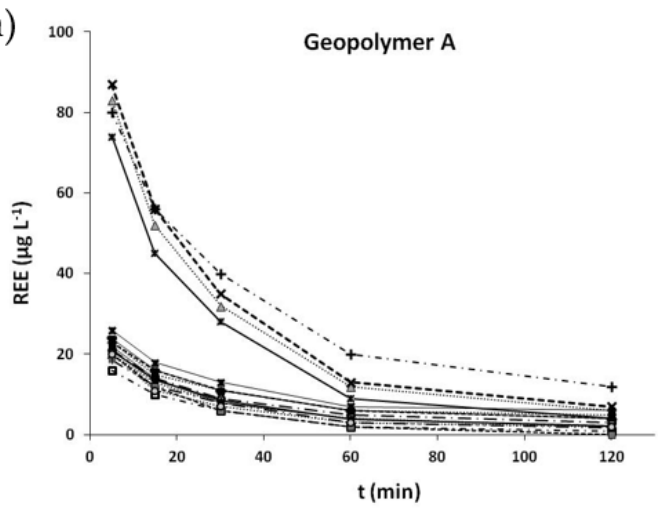

(b)

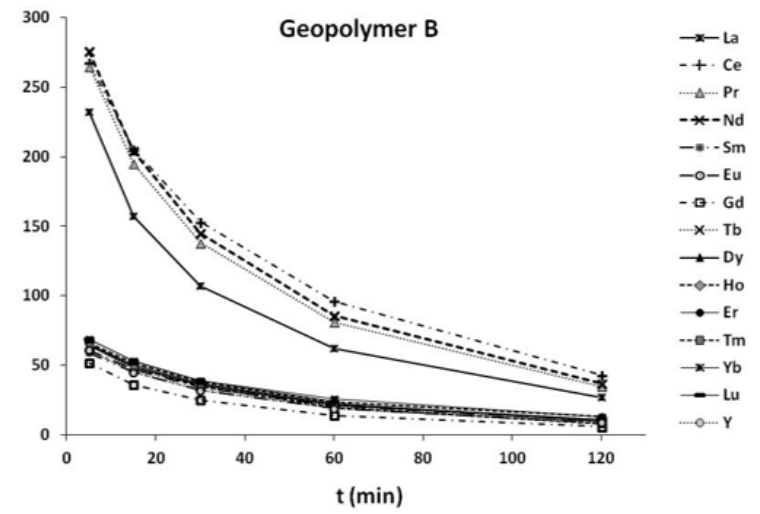

Figure 1. The concentration of rare earth elements (REEs) in solutions $\left(\mu \mathrm{g} \mathrm{L}^{-1}\right)$ after a certain contact time $(t)$ with geopolymers A (a) and B (b).

\subsection{Adsorption Rate Constants}

The adsorption kinetics could be described by first-order kinetic model given in Equation (1):

$$
c_{t}=c_{i} e^{-k t}
$$

where $c_{i}$ and $c_{t}$ represent the initial $(t=0)$ concentration and concentration of REEs after the specific time $t$, whereas $k$ and $t$ represent the adsorption rate constant and time, respectively. The obtained kinetic curves are presented in Figure 2. As can be noticed, they are not equal for both geopolymers; while the sorption of REEs on geopolymer A has two phases, an initial rapid phase followed by a slower adsorption phase that occurred after $60 \mathrm{~min}$, the rates of adsorption on geopolymer B did not vary significantly through the whole experiment. Although the slower adsorption rate that was observed in the second phase (60-120 min) could be attributed to the different properties and 
microstructure of geopolymer A, the most probable explanation for this is the lower concentrations of elements that remained in the solution.

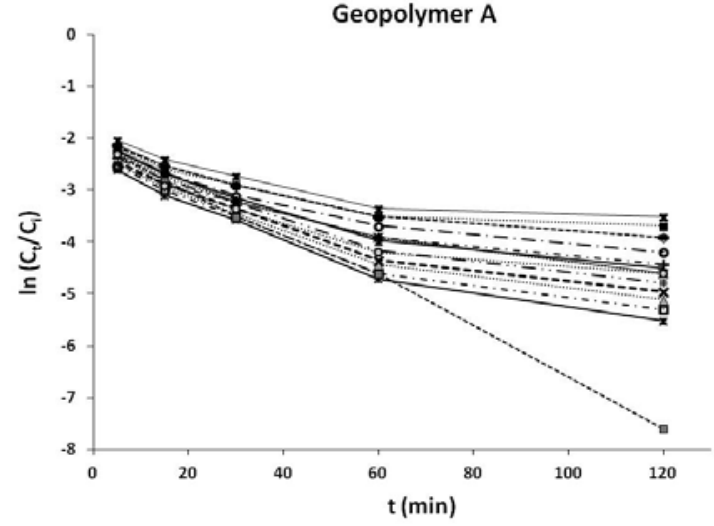

(a)

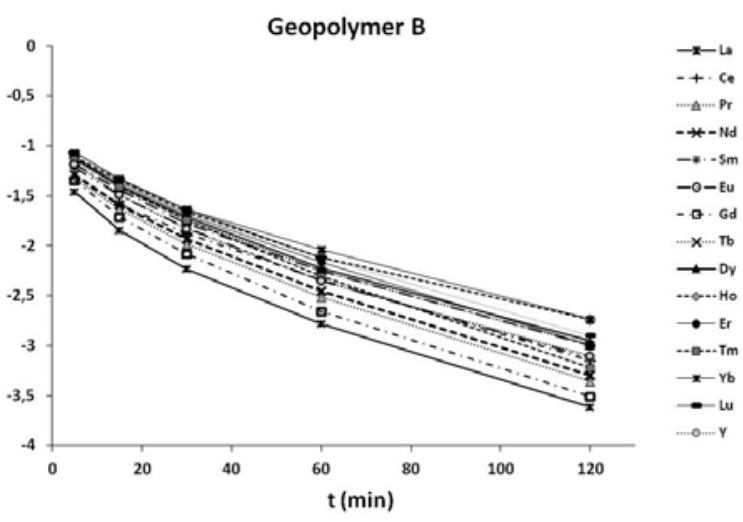

(b)

Figure 2. First-order kinetic fit of REEs adsorption data on geopolymer A (a) and geopolymer B (b).

The adsorption rate constants $(\mathrm{k})$ were calculated using Equation (1) and are summarized in Table 2. The values range from $0.007 \mathrm{~min}^{-1}$ to $0.050 \mathrm{~min}^{-1}$ for geopolymer $\mathrm{A}$, and from $0.010 \mathrm{~min}^{-1}$ to $0.023 \mathrm{~min}^{-1}$ for geopolymer B. Comparing these two geopolymers, it could be observed that the adsorption of REEs on geopolymer $\mathrm{A}$ is faster (up to 2 times) at the beginning of the experiments. After the first $60 \mathrm{~min}$, the rate of adsorption decreased for both geopolymers, although much less for geopolymer B (up to 2 times for geopolymer B, and 3-9 times for geopolymer A).

Table 2. The adsorption rate constants (k) for the studied geopolymers (A and B).

\begin{tabular}{|c|c|c|c|c|}
\hline & \multicolumn{4}{|c|}{$\mathrm{k}\left(\mathrm{min}^{-1}\right)$} \\
\hline & \multicolumn{2}{|c|}{ Geopolymer A } & \multicolumn{2}{|c|}{ Geopolymer B } \\
\hline & $0-60 \mathrm{~min}$ & $60-120 \mathrm{~min}$ & $0-60 \mathrm{~min}$ & $60-120 \mathrm{~min}$ \\
\hline $\mathrm{La}$ & 0.037 & 0.014 & 0.023 & 0.014 \\
\hline $\mathrm{Ce}$ & 0.025 & 0.009 & 0.018 & 0.013 \\
\hline $\operatorname{Pr}$ & 0.034 & 0.012 & 0.021 & 0.014 \\
\hline $\mathrm{Nd}$ & 0.034 & 0.010 & 0.021 & 0.014 \\
\hline Sm & 0.032 & 0.010 & 0.020 & 0.013 \\
\hline $\mathrm{Eu}$ & 0.025 & 0.009 & 0.019 & 0.012 \\
\hline $\mathrm{Gd}$ & 0.037 & 0.012 & 0.023 & 0.014 \\
\hline $\mathrm{Tb}$ & 0.029 & 0.012 & 0.020 & 0.012 \\
\hline Dy & 0.030 & 0.009 & 0.020 & 0.012 \\
\hline Ho & 0.024 & 0.007 & 0.018 & 0.010 \\
\hline $\mathrm{Er}$ & 0.030 & 0.012 & 0.019 & 0.014 \\
\hline $\mathrm{Tm}$ & 0.041 & 0.050 & 0.021 & 0.015 \\
\hline $\mathrm{Yb}$ & 0.023 & 0.003 & 0.017 & 0.012 \\
\hline $\mathrm{Lu}$ & 0.024 & 0.007 & 0.019 & 0.013 \\
\hline
\end{tabular}

The affinity of REEs for the adsorption on the tested geopolymers follows the order of $\mathrm{Tm}>\mathrm{La}, \mathrm{Gd}>$ $\mathrm{Pr}, \mathrm{Nd}>\mathrm{Y}>\mathrm{Sm}>\mathrm{Dy}, \mathrm{Er}>\mathrm{Tb}>\mathrm{Eu}, \mathrm{Ce}>\mathrm{Lu}, \mathrm{Ho}>\mathrm{Yb}$ for Geopolymer A, and the order of $\mathrm{La}, \mathrm{Gd}>\mathrm{Tm}$, $\mathrm{Pr}, \mathrm{Nd}, \mathrm{Y}>\mathrm{Sm}, \mathrm{Tb}, \mathrm{Dy}>\mathrm{Eu}, \mathrm{Lu}, \mathrm{Er}>\mathrm{Ce}, \mathrm{Ho}>\mathrm{Yb}$ for Geopolymer B.

Both geopolymers showed a similar pattern with a higher adsorption affinity for REEs initially present in higher concentrations ( $\mathrm{La}, \mathrm{Pr}$, and $\mathrm{Nd}$ ).

\subsection{Adsorption Isotherms}

Adsorption isotherms describe the partitioning of REEs between the aqueous solution and the sorbent, i.e., the geopolymer. In the present study, the REEs concentrations in geopolymers were determined as the differences between initial concentrations in the solution and concentrations 
measured in the specific time $t$. It was considered that all quantities of REEs that are removed from the solution are adsorbed onto the geopolymers. The evaluation of the data revealed that the adsorption of REEs fit the Langmuir adsorption isotherm described by Equation (2):

$$
\frac{c}{c_{a}}=\frac{1}{b c_{m}}+\frac{c}{c_{m}}
$$

where $c$ represents the REEs concentration in the solution in time $t, c_{a}$ is the amount of adsorbed REEs per unit weight of geopolymer, $b$ is the constant of the Langmuir isotherm related to the equilibrium constant or binding energy, and $c_{m}$ is the maximum amount of REEs adsorbed. The adsorption isotherms shown in Figure 3 demonstrate the linearity in the investigated concentration range for all REEs.

(a)

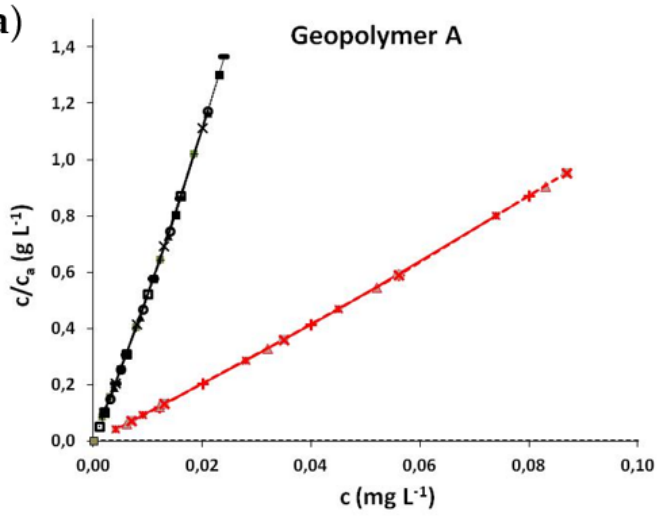

(b)

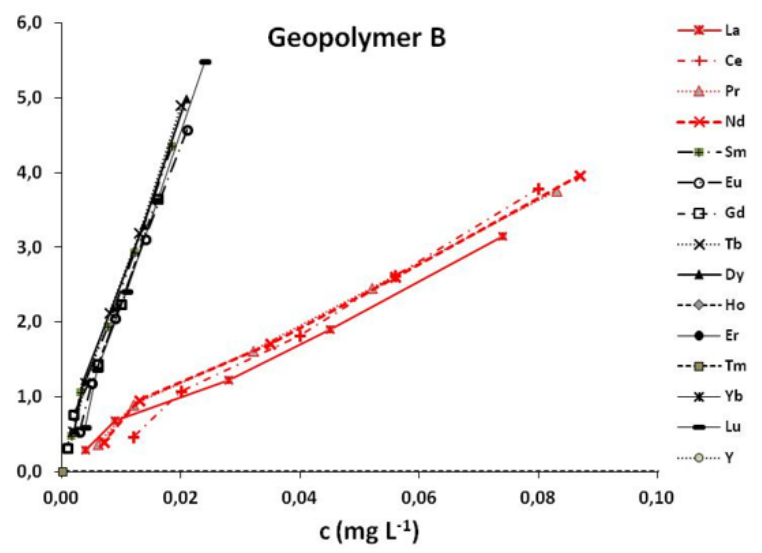

Figure 3. Adsorption isotherms of REEs for geopolymers A (a) and B (b).

The slopes of the isotherms for $\mathrm{La}, \mathrm{Ce}, \mathrm{Pr}$, and $\mathrm{Nd}$ are very similar and are around 5 times lower than those for other REEs, considering both geopolymers. This implies the higher adsorption capacity of both geopolymers for $\mathrm{La}, \mathrm{Ce}, \mathrm{Pr}$, and $\mathrm{Nd}$ compared to the other REEs.

\section{Conclusions}

The obtained results indicate an efficient removal of lanthanides from solution by prepared geopolymers. Although both geopolymers were efficient sorbents for REEs, geopolymer A displayed a slightly better performance compared to geopolymer B. The observed differences between the prepared geopolymers indicate the importance of the preparation procedure, i.e., the composition of the geopolymer and the activators used, in ensuring the optimal adsorption conditions.

In general, the adsorption of REEs on tested geopolymers can be described by the Langmuir adsorption isotherm, whereas REEs initially present in higher concentration ( $\mathrm{La}, \mathrm{Pr}$, and $\mathrm{Nd}$ ), as well as those with lower atomic number (Y, La, Gd, $\mathrm{Pr}, \mathrm{Nd}, \mathrm{Y}, \mathrm{Sm})$, displayed higher adsorption rates.

\section{References}

1. Bau, M.; Dulski, P. Anthropogenic origin of positive gadolinium anomalies in river waters. Earth Planet. Sci. Lett. 1996, 143, 245-255.

2. Lawrence, M.G. Detection of anthropogenic gadolinium in the Brisbane River plume in Moreton Bay, Queensland, Australia. Mar. Pollut. Bull. 2010, 60, 1113-1116.

3. Kulaksız, S.; Bau, M. Rare earth elements in the Rhine River, Germany: First case of anthropogenic lanthanum as a dissolved microcontaminant in the hydrosphere. Environ. Int. 2011, 37, 973-979.

4. Klaver, G.; Verheul, M.; Bakker, I.; Petelet-Giraud, E.; Négrel, P. Anthropogenic rare earth element in rivers: Gadolinium and lanthanum. Partitioning between the dissolved and particulate phases in the Rhine River and spatial propagation through the Rhine-Meuse Delta (The Netherlands). Appl. Geochem. 2014, 47, 186-197. 
5. Bhattacharyya, K.G.; Gupta, S.S. Adsorption of a few heavy metals on natural and modified kaolinite and montmorillonite: A review. Adv. Colloid Interface Sci. 2008, 140, 114-131.

6. Wang, S.; Li, L.; Zhu, Z.H. Solid-state conversion of fly ash to effective adsorbents for Cu removal from wastewater. J. Hazard. Mater. 2007, 139, 254-259.

7. El-Eswed, B.; Alshaaer, M.; Yousef, R.I.; Hamadneh, I.; Khalili, F. Adsorption of Cu(II), Ni(II), Zn(II), Cd(II) and $\mathrm{Pb}(\mathrm{II})$ onto Kaolin/Zeolite Based- Geopolymers. Adv. Mater. Phys. Chem. 2012, 2, 119-125.

8. Al-Zboon, K.; Al-Harahsheh, M.S.; Hani, F.B. Fly ash-based geopolymer for Pb removal from aqueous solution. J. Hazard. Mater. 2011, 188, 414-421.

9. Muzek, M.N.; Svilovic, S.; Zelic, J. Fly ash-based geopolymeric adsorbent for copper ion removal from wastewater. Desalin. Water Treat. 2014, 52, 2519-2526.

10. López, F.J.; Sugita, S.; Tagaya, M.; Kobayashi, T. Metakaolin-based geopolymers for targeted adsorbents to heavy metal ion separation. J. Mater. Sci. Chem. Eng. 2014, 2, 16-27.

11. Davidovits, D. Geopolymer, Green Chemistry and Sustainable Development. The Poly(sialate) Terminology: A very Usefull and Simple Model for the Promotion and Understanding of Green Chemistry: Proceedings of the World Congress Geopolymer 2005; Davidovits, J., Ed.; Institut Geopolymer: Saint-Quentin, France, 2005; pp. 9-17.

12. Van Jaarsveld, J.G.S.; Van Deventer, J.S.J.; Lorenzeni, L. The Potential Use of Geopolymeric Materials to Immobilise Toxic Metals: Part I. Theoty and Application. Miner. Eng. 1997, 10, 659-669.

13. Thomas, P.J.; Carpenter, D.; Boutin, C.; Allison, J.E. Rare earth elements (REEs): Effects on germination and growth of selected crop and native plant species. Chemosphere 2014, 96, 57-66.

14. Hui, K.S.; Chao, C.Y.H.; Kot, S.C. Removal of mixed heavy metal ions in wastewater by zeolite 4A and residual products from recycled coal fly ash. J. Hazard. Mater. 2005, B127, 89-101.

15. Coppin, F.; Berger, G.; Bauer, A.; Castet, S.; Loubet, M. Sorption of lanthanides on smectite and kaolinite. Chem. Geol. 2002, 182, 57-68.

16. Izquierdo, M.; Querol, X.; Davidovits, J.; Antenucci, D.; Nugteren, H.; Fernández-Pereira, C. Coal fly ash-slag-based geopolymers: Microstructure and metal leaching. J. Hazard. Mater. 2009, 166, 561-566.

17. Medunić, G.; Rađenović, A.; Bajramović, M.; Švec, M.; Tomac, M. Once grand, now forgotten: What do we know about the superhigh-organic-sulfur Raša coal? Min. Geol. Petrol. Eng. Bull. 2016, 27-45; doi:10.17794/rgn.2016.3.3.

18. Fiket, Ž.; Medunić, G.; Kniewald, G. Rare earth element distribution in soil nearby thermal power plant. Environ. Earth Sci. 2016, 75, 598, 1-9; doi:10.1007/s12665-016-5410-2.

(C) 2018 by the authors. Licensee MDPI, Basel, Switzerland. This article is an open access article distributed under the terms and conditions of the Creative Commons Attribution (CC BY) license (http://creativecommons.org/licenses/by/4.0/). 